\title{
Research on the Individual Development of Children by Eliminating Stressors
}

\author{
Costica Lupu*
}

\section{ABSTRACT:}

This study presents an empirical research on the identification and observation of the students' manifestations under various circumstances of stress, among which: time pressure, unexpected exam, unknown examiner, overstrain, language.

The research was conducted at the National Pedagogical College "Ştefan cel Mare" from Bacău and consisted in assisting and observing 26 lessons of Mathematics and 26 lessons of Information and Communication Technologies, involving a group of 126 middle-school students and 24 teachers of various specializations.

The tests and questionnaires applied have shown the relevance of becoming aware of the impact of stress, as well as of finding ways to minimize its harmful secondary effects, as many diseases are highly associated with wrong responses, adaptation to stress, external factors, sanctions, failure of the adjustment process, which lead to the onset of illness or unhappiness.

Regarding these problems, we are looking for solutions in the form of best teaching-learning strategies, in order to increase enthusiasm for school activities, decrease the number of school absences, control alcohol, coffee or drugs consumption.

The 20 students in the third year from the Faculty of Mathematics, "Vasile Alecsandri" University of Bacău, have conducted a research during their pedagogical practice included in their initial teacher training. The research has focused on emotional intelligence and implied direct observation of the students' behaviour during an unannounced test at Mathematics, with the subsequent application of a questionnaire.

Keywords: stress, fright, anxiety, evaluation test, psychological test, mathematics

\section{INTRODUCTION}

This study supports us in understanding the challenges with which students are faced in their school life and the methods which may help them achieve higher performances without too many difficulties. Since new situations are seen as stress agents, they should be staged in a less official frame, in order to accustom the student first. The diversity of novel situations is even more necessary as it may support the student in preparing for professional life. Hence, we believe that a pleasant working atmosphere in initial situations could support the group in adapting to stressful situations and reach higher work efficiency levels.

*Vasile Alecsandri" University of Bacau, Department of Mathematics-Informatics and Science of Education, Calea Mărășești, No 157, 600115, Bacău, Romania

(C) 2014 Costica Lupu; licensee IJIP. This is an Open Access Research distributed under the terms of the Creative Commons Attribution License (http://creativecommons.org/licenses/by/2.0), which permits unrestricted use, distribution, and reproduction in any Medium, provided the original work is properly cited. 
This paper describes an experimental research on the effects of stress upon the students' attitude and learning by introducing stress factors in the learning experience. Our research aims at investigating the impact of applying stress factors to the building of learning attitudes and the relevance of using efficient learning strategies by the use of combinations of specific methods, techniques and procedures, in order to contribute significantly to the development of the students' thinking and the improvement of their mathematical results.

In order to research, analyse and describe a wide range of perspectives, the research team, consisting of 20 students from the Faculty of Mathematics, attending their initial teacher training programme, will apply tests and questionnaires at different moments during their teaching practice stage.

\section{THEORETICAL BACKGROUND}

\section{Definition of stress}

The term of stress occurs increasingly often in our present vocabulary, with a double use: one referring to a stressful situation (the harmful, aggressive circumstances which assault or threaten the body, the pressure, constraints and deprivation affecting the individual); the other one referring to the bodily condition of stress (suffering, wear, stress agents).

If the stress factors are unusual, unexpected, and aggressive and threaten the student's psychic state, then we are dealing with a stressful situation, but an exam, competition or even dental treatment may exert a stressful effect even before the proper action.

In his work, Treaty applied psychology, the French psychologist Piéron H. (1881-1964), Professor at the University of Paris, identifies stress with aggression or violent action upon the organism, brutality, the menacing nature of the situation as general particularities of the stressful circumstance.

Golu M., in his work entitled Neurophysiologic bases of the psyche, Bucharest, Ed. Scientific,1982, defines stress as a state of tension, anxiety and discomfort generated by negatively charged emotional factors, frustration or repression of motivation, difficulty or impossibility in solving problems.

Another brief, simple definition of stress is provided by Selye, H. 1991, History and present status of the stress concept, after A. Monat and R.S. Lazarus (eds), Stress and Coping , ( $3^{\text {rd }}$ ed.) New York: Columbia University Press, 21-35: any life situation, which demands effort from the mechanism, generates stress.

If the accent falls on the condition of the body and its reactions, we are usually considering excessive emotional responses, changes in responsiveness, which are visible in the individual's behaviour, language, the deviation of various psychological or physiological parameters. From 
this perspective, stress occurs in any situation in which the good condition of the body or its physical and psychic integrity is threatened, the individual having no ready-made answers to reduce the threat.

The term of adaptation has multiple meanings, in Biology, Psychology, Physiology. Physiological adaptation is defined by William Lloyd Prosser (1898-1972), noted American law professor and author of Prosser on Torts, as any property of an organism which supports survival in a specific environment, in a particular way, in a stressful environment. For Lazarius, psychic survival means adaptation to demands and social or interpersonal pressure, as well as internal biological and social - pressure, the need for approval, achievement. Ultimately, the notion of adaptation implies the maintenance of the body's integrity and its dynamic balance in relation to the surrounding environment.

The condition of psychic stress is, in reality, a psycho-physiological stress; we cannot perceive stress as purely physical, just like we cannot perceive it as having purely physiological effects. Whatever the specific objective of an analysis, adaptive mechanisms involve the interrelation, interaction between the two.

We have all experienced moments when we realised that we are suffering from fright in situations we have never been faced with before. The explanation is simple: we are born with genetic equipment, characteristic for our species, meant to protect us. Within this equipment, anxiety holds a large share. Since our fellow human beings represent a quite relevant source of dangers, it makes sense that social anxiety and, particularly, performance anxiety occurs within a defence system.

But, although we are all born with this vulnerability of experiencing anxiety at the moment of the action, few of us know the pathological stage. This vulnerability, combined with many life experiences, makes some individuals avoid fright situations.

Fright as a determined reflex: we are all pre-conditioned and we realise this if we notice the majority of our automated gestures, which we perform on a daily basis. We say "hello" when we pick up the receiver, we look to the left and to the right before crossing the street, we sit in the same way when we reach our office in the morning etc. Why? We have assimilated these events and, eventually, their results have turned out quite satisfactory in order to be regarded as profitable. But, why does a situation, which is essentially not dangerous or represents a minor risk, cause such intense reactions?

In most cases, children do not have proper training to face the judgments related to them during studies. Usually, teachers behave like judges. Only seldom do they understand how the psychic system of their audience works. Children reason based on the system "all or nothing", experiencing feelings of full success or complete failure. Relativization is not their strongest 
asset, except when teachers or parents teach them this thing. For example, from an early age, children are asked to recite a poem in front of the whole class, just like in music schools, they are asked to take part in "auditions", although they do not yet master the instrument too well. There is, therefore, an actual hostile stimulus (the judgment of the audience and, along with it, the feeling of rejection or abandonment) and, consequently, a reaction of anxiety. As a consequence, the simple fact of finding yourself in a public situation triggers the anxiety.

If the person suffering from fright regularly manages to deliver a public speech, he will activate his strengthening systems, will be able to associate the respective situation with a state different from anxiety. He will gain more self-confidence. The more public speeches he will deliver, the more durable and fast will the change generated by his actions (what he does) be, the more aware he will become of his competences, the greater will be his self-confidence.

\section{The phases of stress}

From the moment of its occurrence and to its final phase, stress covers three stages:

1. The alarm phase is the stage during which notification of the presence of a stressful agent is made. The physiological reactions represent the first response meant to warn the person about the need of being on guard, so that, by evaluating the situation, the individual may face and solve the problem in a satisfactory way, to prevent materialization.

When stress overcomes the individual's power, he becomes aware of its presence and may take measures to solve the problem in a satisfactory way.

2. The resistance phase is the stage during which stress extends its presence beyond the initial alarm phase and the stressed person loses more energy, his performance reduces, therefore he suffers and becomes anxious, thinking about the possibility of failure.

3. According to Melgosa's paper, No stress, there is also the phase of exhaustion, the final stage of stress, characterised by fatigue, anxiety and depression, often occurring separated or together [9].

\section{The forms of anxiety}

Most of the risks undertaken by students in school or family bring along various degrees of failure threat, so that they tend to generate a certain degree of anxiety. Anxiety also emerges during the transition phases of building personality, during the transition from childhood to adulthood, from primary to middle-school, from middle-school to high-school and less from high-school to university.

Anxiety is caused by an internal, objective threat to self-esteem, possibly arising from the individual's conscience regarding the value of some of his moral ideas, but, sometimes, the threat may come from the exterior. What is relevant about these cases is the fact that the threat is capable of damaging the sense of personal dignity of normal individuals.

Normal anxiety may be classified as follows: 
a) Anxiety before the change may occur before an exam or competition. The anxiety before change makes the transition from an inconvenience to a reaction of repulsion, illness, moral threat. Anxiety is characterized by agitation, discouragement, sweating, fantastic dreams during sleep, difficult and cumbersome organization of ideas, the impression that problems are insurmountable, complicated. Anxiety before change triggers a disturbance of sensitiveness when faced with change, reverberating upon the activity.

b) Anxiety after the change may occur in relation to a new job, change of home, a new family situation. Anxious people are afraid of the announced change, do not understand it, refuse and reject it. Any modification of the person's status, which is rather slow, cannot trigger these bouts of anxiety, because habits may follow the direction of change, and if manifested fast enough, such changes may turn into real anchors for future activities. The respective person may face the situation more easily than expected. But, sometimes, anxiety may reoccur after an action, because, for example, following an exam, the person may wonder whether he had committed some mistake or, following a conversation, the person may wonder whether he could have upset the interlocutor.

c) School anxiety is characteristic of school activity and occurs as a result of a series of failures that are neither the consequence of the student's poor intelligence nor his lack of interest. School anxiety is often related to maladjustment to school requirements, because school implies a continuous transition from what has been learned to new knowledge and applications. These serial changes lack security, because an unknown problem, an unpredicted question, the teacher's sudden interpellation by the teacher, a new teacher, going to the blackboard are, for some persons, elements of anxiety and stress.

School is not the only one responsible for school anxiety. Although it is experienced at school, school anxiety occurs also due to the parents' demands. School anxiety may be triggered by the following factors: the person's anxious tendency, the family's anxiety, the teachers' anxiety.

\section{The effects of stress}

The effects of stress may be displayed in the following areas:

a) The cognitive area, manifested through: - the difficulty to stay focused over a longer time span, for a more complex activity; - the frequent loss of attention; - poorer memorization ability; - a problem requiring immediate and spontaneous reaction will be solved with difficulty, over a longer time span; - any problem requiring logical thinking will be solved with multiple errors; the mind is incapable of deep analysis and accurate evaluation; - disorganized thought.

b) The emotional area, manifested through: - difficulty in staying physically and emotionally relaxed; - increased impatience, intolerance and authoritarianism and lack of consideration for others;

- moral or ethical principles become looser and self-control diminishes; - discouragement increases and the desire for life decreases; - there occur feelings of incapacity and inferiority.

c) The behavioural area is related to aspects such as: - inability to express oneself verbally by means of sentences and phrases, decreasing the speech flow; - loss of enthusiasm for one's 
favourite activities, hobbies or recreational entertainment; - absence from work or school; increased use of alcohol, tobacco, coffee and drugs; - decreased level of energy; - poor sleep, increased levels of insomnia; - enhanced tendency to suspect everyone and everything; - the tendency to blame others for one's own mistakes; - the occurrence of strange tics and reactions, which are not characteristic of the person; - suicidal thoughts.

Among the stress factors we may also mention: overload, down weight and time.

Overload through excess of stimuli generates psychic stress when the action of the stress factors is overwhelming, in terms of number, duration and intensity, natural condition. The abruptness and unpredictability of the stimuli cause acute stress (a fire, the loss of a dear person). However, chronic stress intervenes most often when the tension does not reach unbearable intensities but extends for longer periods of time. This category includes the environmental factors (high temperature at work, noise etc.)

Down weight stress is generated by the change in certain work related factors. Prolonged training under circumstances of isolation is a condition which restricts more or less not only the diversity of physical environment but also the possibility of choosing new physical and social stimuli.

The factor of time plays a leading role, because there are people who can handle serious stress over a relatively short period of time, but cannot adapt to a lower intensity but prolonged stressful situation. In the latter case, there occurs latent psychic stress, which becomes manifest in less serious situations, as a result of temporal summation. Research has shown that from the cessation of the conflicting situation until the manifestation of the first signs of neuropsychiatric disorder there is an amount of time during which behaviour is apparently normal. The issue deserves a special study because there are data showing that fear or anxiety keeps growing even after the elimination of the stressful situation. Sometimes, there is a decrease in performance 6-7 hours after the cessation of the action of stress agents, indicating a real incubation of fear.

Even in the case of time pressure, it is not the approach of the deadline but the threat of failure, the eventual punishment for not complying with the deadline, which is the real stress factor. The threat also depends upon the importance of the task. We may follow a dynamics of the nervous tension according to the discrepancy between the point where one finds himself solving a problem and the point where one should be in solving the problem at a given moment.

\section{THE RESEARCH METHODOLOGY}

\section{The objectives of the applicative research}

Identification and observation of students under various circumstances of stress, among which: time pressure, unexpected exam, unknown examiner, overload.

Interpretation of language and bodily posture, as well as of the results to the test and questionnaire. 


\section{THE HYPOTHESES OF THE APPLICATIVE RESEARCH}

Acknowledged decrease in work performance under stressful circumstances is shared by both adults and children. In our case, the student is exposed to several stress factors, due to his being faced with more unknown stimuli than adults. Time, overload, competition are met with on a daily basis in education. That is why, it is necessary to prepare students for stressful situations by means of interactive, relaxation or imagination exercises. In this way, students are given the possibility to know themselves and the others sharing the work environment.

\section{Characterization of the experimental group}

The research group comprised $48^{\text {th }}$-grade classes ( 2 experimental, 2 control), where 20 students in the third year from the Faculty of Mathematics, the programme of initial teacher training, have conducted, during their teaching practice hours, assistance, probation and final lessons. There was also achieved a process of individualizing the instructive-educational act, given the fact that true pedagogical art results from the student's ability to harmoniously combine active-formative strategies, the children's individual development with the elimination of the stress factors.

\section{THE RESEARCH STAGES}

The experimental research was conducted during the 2013-2014 school year and covered three stages:

- The stage of initial evaluation was conducted between October 20-27, 2013. During this stage, there were applied tests which aimed to identify the initial level of development of the ability to solve parallelism problems in the context of the presence of stress factors.

- The ameliorative stage was conducted between November 112013 -April 30 2014. During this stage, there were organized and conducted lessons of Mathematics, frontally as well as individually and in small groups. It aimed at identifying the cognitive, psycho-motor and socioemotional elements, and focused on the development of the ability to solve parallelism problems by progressively diminishing the stress factors.

- The stage of final evaluation was conducted between May 15 - June 11, 2014. During this stage, there were designed, adapted and applied tests in order to establish the progress of children at the level of their ability to solve problems of parallelism in space with the full elimination of stress factors.

\section{RESEARCH METHODS AND TECHNIQUES}

To verify the hypothesis and achieve the research objectives, the students have applied the following research methods and techniques: the questionnaire, observation, the psychopedagogical experiment with the method of the test, conversation, the method of the analysis of the activity products and research of documents, the method of the test, as well as the techniques of presentation and mathematical-statistical processing of the research data.

The research methods were used in order to evaluate the mathematical level of training and responses of 80 middle-school students from "Octavian Voicu" Middle-School of Bacău, during 
the 2013-2014 school year, regarding the use of the new technologies and recording the attitudes and competences of the 20 university students in relation to the teaching-learning-evaluation of parallelism in space.

\section{THE APPLICATIVE RESEARCH METHODOLOGY AND THE ANALYSIS OF THE OBTAINED RESULTS}

Because the subjects of the investigation are 80 students in the $8^{\text {th }}$ grade, the method selected for researching emotional intelligence is direct behaviour observation during an unannounced Math test and the method of the questionnaire.

Observation implies knowledge and examination of the students' behaviour, in order to obtain the necessary data about the different levels of stress of students and their responses during an unannounced exam. Each student has displayed either immediate reactions (manifesting a sudden increase of the level of stress), or a progressive increase throughout the duration of the exam.

Given the fact that the evaluation test for Mathematics on parallelism in space was from the beginning a difficult task, meant to highlight the students' reactions and establish a percentage of efficiency under circumstances of utmost stress, we do not expect accurate and complete solutions to the test.

We shall further present the initial evaluation test on parallelism in space for the $8^{\text {th }}$ grade, applied after having created stressful circumstances:

1) Establish the value of truth (True/ False) of the following sentences: $a, b$ are lines, $\alpha$ and $\beta$ are planes): (2p)

a) $a\|\alpha, a \subset \beta, \beta \cap \propto=b \Rightarrow a\| b \ldots \ldots \ldots . . . \quad$ b) $a\|\alpha, b \subset \beta \Rightarrow a\| b$

c) $a\|\alpha, \alpha\| \beta \Rightarrow a \| \beta$

d) $a \| b, a \cap \alpha=\{P\} \Rightarrow b \nVdash \alpha$

2) Two planes parallel with a third plane (distinct from the first two) are (choose the correct answer or answers): a) parallel all three of them; b) perpendicular among them; c) secant.

3) Establish, by arrows, the correspondence between statements and answers:

(4 p) 
Research on the individual development of children by eliminating stressors

\begin{tabular}{|l|l|}
\hline Statements & Answers \\
\hline $\begin{array}{l}\text { Two parallel planes determine on two parallel } \\
\text { lines they intersect }\end{array}$ & the two planes are parallel \\
\hline $\begin{array}{l}\text { If two parallel planes are cut by a third plane, } \\
\text { then }\end{array}$ & respectively proportional segments \\
\hline $\begin{array}{l}\text { If a plane contains two concurrent lines parallel } \\
\text { with another plane, then }\end{array}$ & congruent segments \\
\hline \multicolumn{1}{|c|}{ Fill with } & in the missing words: \\
\hline
\end{tabular}

$(2 \mathrm{p})$

a) Given a line $a$ parallel with plane $\alpha$, and $\alpha$ a plane containing line $a$. Then $\alpha \| \beta$ or $\beta$ by a line with $a$.

b) Given a line $a$ included in or parallel to a plane $\alpha$ and a line $b$ parallel with $a$, drawn through a point A of plane $\alpha$. Then line $b$ is

Note: 1 point from the office. Time: 30 minutes

We present the final evaluation test on space parallelism for the $8^{\text {th }}$ grade, without the application of stress circumstances:

We have proposed the following evaluation test for the final test:

Consider the cube $\left[A B C D A^{\prime} B^{\prime} C^{\prime} D^{\prime}\right]$ and points, $M$ the middle of edge $[\mathrm{BC}], \mathrm{P}$ the middle of edge [AA'], $O$ the centre of side [A'B'C'D']. (Fig. 1)

1. Establish the truth value (True/ False) of the following sentences:

$(2 \mathrm{p})$
a) $A B \| D^{\prime} C^{\prime}$
b) $A B B^{\prime} A^{\prime} \| C D C^{\prime} D^{\prime}$,
c) $A B \| C D C^{\prime} D^{\prime}$
d) $A B \| E F$,

2. Planes $A B C D$ and $A B B^{\prime} A^{\prime}$ are (choose the correct answer/ answers): a) parallel to one another;

b) perpendicular to one another ; c) secant.

$(1 \mathrm{p})$

2. Identify the shape of the section polygon determined in the cube by plane (MPO). (2p)

3. Determine the area and perimeter of this section.

$(4 \mathrm{p})$ 
Note: 1 point from the office. Time: 30 minutes

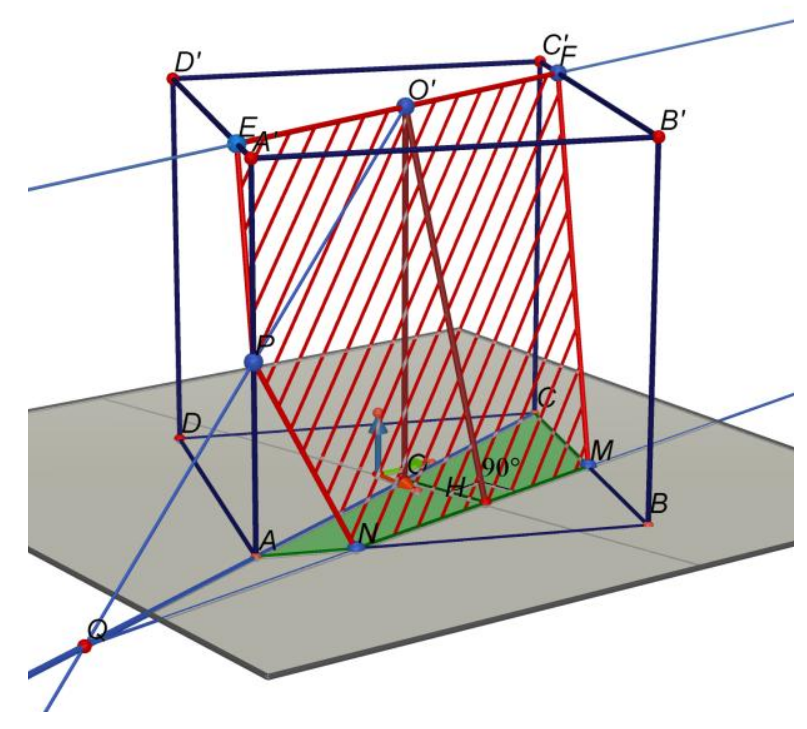

Figure 1. The section determined by plane (MPO).

Comparing the results to the tests applied in the initial, formative and final evaluation, we have found that the children's performances have grown along with the removal of the stress factors.

Below is the comparative presentation of the evolution of the results obtained in the Mathematics tests, shown in order to highlight the relevance of eliminating stress factors.

\section{Comparative graphical representation of the evolution of the school results obtained} throughout the intervention

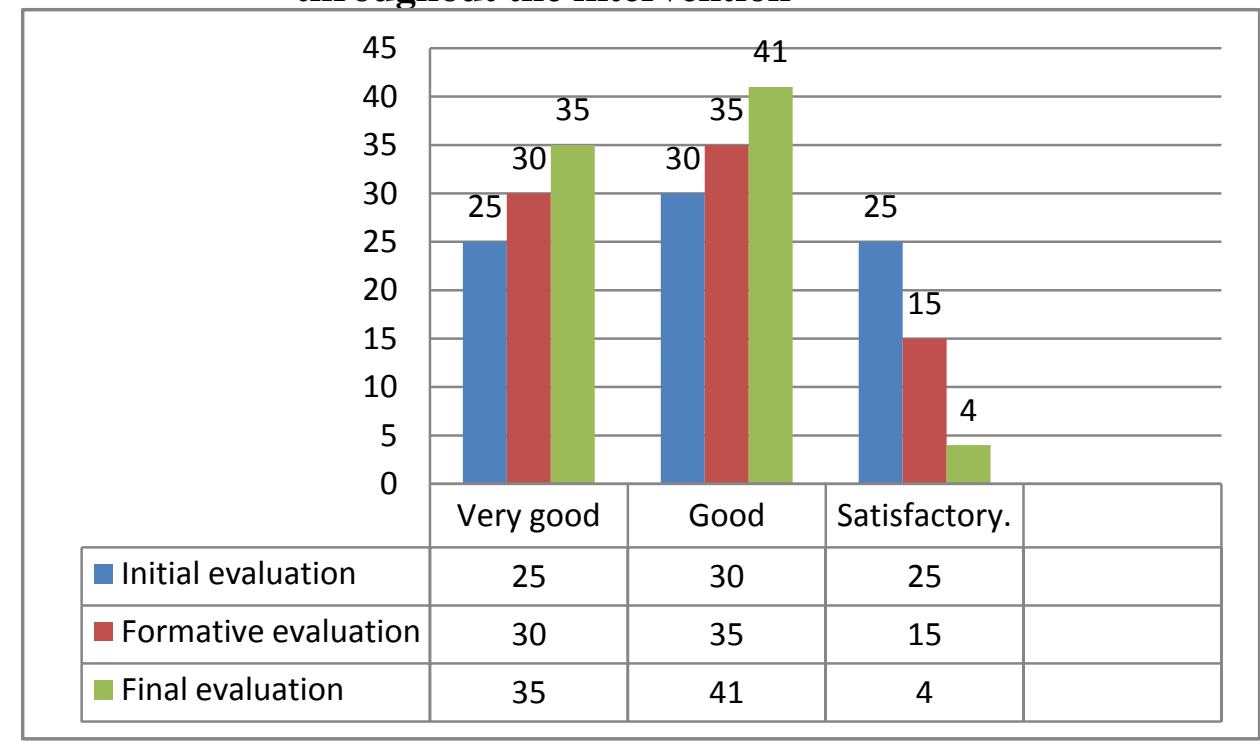


Comparing the results obtained for the 3 evaluations at Mathematics (initial, formative and final), we have found the following: in the initial evaluation, 25 students $(31,2 \%)$ have obtained the mark very good, 30 students $(37,6 \%)$ the mark good and $25(31,2 \%)$ the mark of satisfactory; in the formative evaluation, 30 students $(37,5 \%)$ have obtained the mark very good, 35 students $(43,7 \%)$ the mark good and 15 students $(18,7 \%)$ the mark satisfactory; in the final evaluation, there prevails the mark of very good with 35 students $(43,7 \%)$, the mark of good increases, 41 students $(51,3 \%)$ whereas there has been a drastic decrease of the mark satisfactory, with only 4 students $(5,0 \%)$.

The results obtained in the initial test have constituted the basis for designing, organizing and conducting the activity throughout the lessons conducted during the teaching practice, thus efficiently ensuring feed-back, which led to school progress.

By their results to the final test, solved under circumstances of absence of stress factors, the students have demonstrated that in a pleasant atmosphere, their ability to operate logically using proper informational language has increased. By applying measures to improve the results by gradually eliminating the stress factors, and the adaptation of the learning activities to the individual characteristics and unique development rhythm of each child, higher levels of efficiency were reached and the established objectives achieved.

Instead, the psychological test was aimed at observing the same students in a completely stressfree situation. The work task was completed surprisingly fast and reactions showed more openness towards a continuation of work in relation to the first task.

The method of the psychological test supported the identification of uncompleted tasks or solutions that were wrong to various degrees, according to the adaptation of each child to stress. In four cases, the lack of motivation led to the lowest level of solving the questionnaire.

\section{Psychological test. How do you respond to stress?}

1. You have been feeling exhausted for a long time? 1 - Yes; 2 - No

2. Have you had moments in which you felt overwhelmed by the situation? 1 - Yes; 2 - No.

3. What is, generally, your psychic state like? 1 - Excellent; 2 - Good; 3 - Bad;

4. Do you often feel "hot and cold waves"? 1 - Yes; $2-$ No.

5. Have you suffered from speeded heartbeat? 1 - Often; 2 - Sometimes; 3 - Never.

6. How is your appetite? 1 - Weak; 2 - Normal; 3 - Strong; 4 - Too strong.

7. You are so tired that you cannot even sit on the chair. $1-$ Yes ; $2-$ No.

8. Are you the type of person who worries about anything? 1 - Yes; 2 - No.

9. Have you had breathing difficulties? 1 - Often; 2 - Sometimes; 3 - Never.

10. Have you had crises of nervousness? 1 - Often ; 2 - Sometimes ; 3 - Never.

11. Have you suffered from faintness? 1 - Never; 2 - Very seldom; 3 - Seldom.

12. Do you have difficulties in falling asleep? 1 - Often; 2 - Sometimes; 3 - Never. 


\section{Research on the individual development of children by eliminating stressors}

13. Have you been bothered by gastric acidity (for several days in a row)? $1-$ Yes; $2-$ No.

14. Do you have good memory? 1 - Yes ; 2 - No.

15. Did it happen to you to suffer from cold sweat? 1 - Often; 2 - Sometimes; 3 Never.

16. Do your hands shake visibly ? 1 - Often; 2 - Sometimes; 3 - Never.

17. Do you hear noises in your head all the time? 1 - Yes; 2 - No.

18. Do you suffer from personal fears which cause mental breakdown? $1-$ Yes; 2 - No.

19. Do you feel isolated even among friends? $1-$ Yes ; 2 - No.

20. Nothing happens as you wanted. $1-$ Yes; $2-$ No.

By applying the method of the case study, it was assumed that stress may be due to the fact that the reward does not certify the effort. But, research has not confirmed this point of view, because even a great reward after a successfully completed task does not necessarily remove the stress. No direct connection has been established between psychic stress and the reward itself, although the threat of losing the reward applies a stressful impact. In turn, the very consequences of work - success or failure - play a more relevant role compared to the external reward. They occur as stress factors, which are stronger than the volume of work or its difficulty. The same intellectual task is regarded as recreational if it is found in a crossword magazine, but becomes stressful when included in psychological tests for determining the intellectual level or for admittance competitions. Emotional motivation and tension is different in the two situations.

Calculating the score and interpreting the results was achieved according to the following rules: 1 point for selecting answer 3 from item 3 , answer 3 from item 11 and answer 2 from item 14. For each of the other items, 1 point was scored for the selection of the first answer (answer 1). The results were categorized as follows : between 0 and 3 points, normal response to stress; between 4 and 6 points, response to stress on the borderline of normality; more than 7 points, serious discrepancy between requirements and personal abilities.

The percentage analysis of the questionnaire results has indicated that: $37,7 \%$ of the students respond normally to stress; $44,2 \%$ are on the limit of normality in relation to stress factors; only $18,1 \%$ of the students display serious discrepancy between requirements and personal abilities.

\section{CONCLUSIONS}

Stress is associated with every situation implying effort. The greater the effort and the more numerous the stress factors, the lower the performance. The human psychic and physical reactions may be of help, but these may also decrease work volume and quality. In order to support children in a sustainable way, we recommend taking into consideration the student's personality and the external factors which may induce panic. Previous psychological training is necessary in order to reach maximum levels of work, under bearable stress conditions.

It is not enough to know what to communicate or to know your students well. A good teacher is characterized by sympathies, the ability to seize and understand the students' needs and problems, empathize with them, adapting his teaching and emotional behavior to their needs. 
In order to build an authentic sympathy relationship between himself and the students, the teacher needs certain qualities: interest in children and the desire to help them prepare for life, passion and dedication, soul balance, honesty, professional competence and a modern pedagogical approach.

It is interesting that many subjects solve problems much faster and more correctly if they are allowed to work at their own pace than if time pressure is applied. The explanation lies, among other things, in the stress generated by exaggerated emotional response, which disturbs efficiency.

\section{REFERENCES}

5. Chneiweiss, L., Tanneau, E., (2006), How to let go of Thracian, Three Publishing, Bucharest.

6. Cojocariu V. M., (2002), Theory and Methodology of Training, Teaching and Pedagogical Publishing, Bucharest.

7. Cristea, S., (2003), Fundamentals of educational sciences. The general theory of education. Editorial Group Point / Point International, Chisinau, Bucharest.

8. Dobrescu T., (2006), Dimensions of communication through body language, Tehnopress Publishing House, Iasi.

9. Dumitriu Ghe., (2001), General Psychology, Bacau.

10. Floru, R., (1974), Psychological stress, Romanian Encyclopedic Publishing House, Bucharest.

11. Lupu, C., (2011), Mathematics teaching, volumes I-II, Alma Mater, Bacau.

12. Lupu C., (2008), Pedagogical paradigm of school subject didactics, Didactic and Pedagogic Publishing, RA, Bucharest.

13. Melgosa J., (2000), No Stress, Life and Health Publishing House, Bucharest,

14. Www.rasfoiesc.com/Managementul classroom-management stress. 